$\xi=2$

\title{
Platelet-rich fibrin-a cost-effective, donor less and indigenous therapy for obtaining root coverage-a case report
}

\author{
Joshi Bharat * \\ Set No 116, Phase 3, HIG Himuda colony, Baddi, tehsil Nalagarh, Distt. Solan, Himachal Pradesh, India, Pin code- 173205 \\ *Corresponding author E-mail: bharatrimpu@gmail.com
}

\begin{abstract}
Among the periodontal infections, gingival recession is a separate clinical entity which demands a permanent solution plan. Treatment therapies are based on either elimination (as in case of Miller's class I/II recession) or increasing the width of keratinized gingiva for prevention of further progression (as in case of Miller's class III/IV recession). From the centuries, graft surgeries like free gingival graft, lateral pedicle and Coronally advanced flaps have been successful in the treatment of gingival recession. As every technique has its own merits and demerits, clinicians have tried to stress upon addition of certain adjuncts or biomaterials to ensure rapid healing and less postoperative discomfort. Platelet concentrates are an excellent biomaterials for increasing width of attached gingiva and enhancing wound healing. They are cost effective, do not require donor tissue for harvesting and contain variety of growth factors for initiating regeneration. In this paper, Platelet-rich fibrin a 2nd generation concentrates has been used as an adjunct to Coronally advanced flap with a purpose of increasing width of keratinized gingiva, obtaining complete root coverage and achieving gingival harmony.
\end{abstract}

Keywords: Fibrin; Coronally Advanced Flap; Healing; Platelets; Growth Factors

\section{Introduction}

Oral diseases comprise of vast array of destructive processes, which are chiefly concerned with either pulpal or periodontal pathology. Pulpal infections, majorly; manifest themselves as either reversible or irreversible pulpitis while periodontic infections initiate in the form of gingivitis or periodontitis. Pulpitis is easily treated by root canal treatment or ultimately by extraction, but periodontal infections have a different strategy for cure \& prevention. Often patients present with dentinal hypersensitivity which upon clinical observation demands a permanent treatment therapy. This condition is commonly referred to as 'Gingival recession' which is characterized by exposure of root surface by an apical shift in position of gingiva (Newman et al.2014, p.735).

Gingival recession is a challenging task for clinicians because in some cases, esthetic concerns are the primary treatment modality besides elimination of dentinal sensitivity. Probably, there can be chances of even root caries (Raetzke1985, p.397).Hence, Hentreatmentrbecomes essentialsfortpreservingeoralihealth. Whilehcompletecrootecoverageccanrbeeachievedainiboth Class,hI Cands III Miller'sMgingivalgrecessionedefects, donlytpartial coveragecmayrbeeexpectedeineClassi IIIl and ClassnIVCMiller'sMgingivalgrecessionedefects (Newman eteala.2014,1 p.1931) p.1931)

An ideal outcome of a root coverage procedure can be achieved only if the environment is plaque free (on tooth surface) and adequate periodontal support is present (Raetzke PB1985, p.397-402). Another important clinical entity is the amount of keratinized gingivae, which prevents further progression of gingival recession (Newman et al.2014, p.1948) Hence, all these components must be considered for restoring periodontal health.
The therapeutic modalitiesinclude pedicle soft tissue graft procedures (advanced or rotational), or free soft-tissue graft procedures (epithelialized graft or sub-epithelial connective tissue graft) (Lindheet al.2008,p.972-977)Further, rotational flap procedures are differentiated into the laterally sliding flap, double papilla flap and oblique rotated flap while the advanced flap procedures are subdivided intocoronally advanced flap and semilunar coronally advanced flap. As every surgical procedure has both advantages and disadvantages, selection of cases remains the key for elimination of gingival recession. The free gingival graft is always associated with painful post-operative palatal wound and unpleasant aesthetics (due to harvesting of graft from a palatal mucosa) while lateral pedicle graft results in occurrence of recession at the donor site (Miller 1988, p.674-681; Sato 2000,p.342).On the other hand, Semilunar coronally advanced flap ,though suture-less, is successful in maxillary arch only while Coronally advanced flap (CAF) is associated with shortening of vestibule (Miller 1988, p.674-681). Furthermore, sub-epithelial connective tissue (SCTG), which remains the gold standard for root coverage (mean root coverage between 52 and $98 \%$ ), is a technique sensitive procedure and requires a second site (donor) for harvesting of graft, which is not always possible (Sato 2000,p.365; Paulo et al. 2001,p.84-88).

Emphasis has always been there for creation of additive materials for accomplishing goals of root coverage. Various clinicians have used certain adjunctive agents such as, root conditioners (e.g. citric acid and tetracycline), enamel matrix proteins, recombinant human growth factors, platelet-rich plasma (PRP) and platelet-rich fibrin (PRF) (Bernimoulinet al.1975 p.2;Zucchelliet al.2004 p.1734, Huanget al.2005,p.1768,Castellanoset al. 2006 p.7, Kanakamedalaet al.2009,p.50).Autologous concentrates have proven to been excellent adjunctive healing biological materials for graft procedures (Urazet al.2013,p.1) 
The initial concept of these autologous preparations was to concentrate platelets, growth factors in a plasma solution and lastly, activate it into a fibrin gel on a surgical site so that local healing is improved(Zhao et al.2013, p.3).Platelet-rich fibrin (PRF), which was first discovered by Choukroun et al (2001)of France, is a second generation platelet concentrate, and it has been used significantly in the field of periodontal plastic surgery (Dohanet al.2013,p.38-40) Many clinicians have performed Coronally advanced flap along with platelet-rich fibrin (PRF) for the treatment of gingival recession and found that PRF can be used effectively for root coverage as well asa healing biomaterial(Urazet al. 2013p.1; Kumar et al.2013 p.631, al.2015,p.66).

This case report signifies the additional benefits of platelet-rich Thamaraiselvanet fibrin membrane as an adjunct to Coronally advanced flap for managing gingival recession. Further, an orthodontic button was also applied for maintaining the stability of flap (Marooet al.2014, p.132).

\section{Case report}

A 43 years-old male came to the Department of Periodontology, Bhojia dental college \&Hospital, Baddi, with a chief complaint of

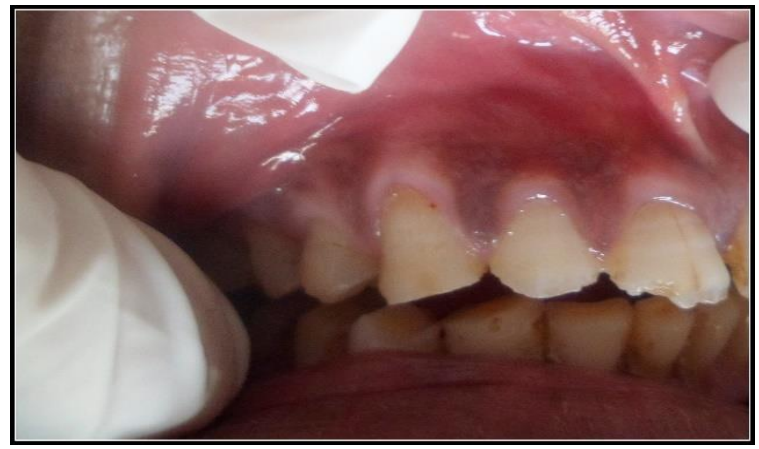

Fig. 1: Pre-Operative View of Class I Gingival Recession on Tooth No. 13. unpleasant looks in right upper front tooth region. On clinical examination, it was noticed that there was attrition present along with Miller's class, I gingival recession with respect to right maxillary canine (tooth no.-13). Pre-operative recession width (RW), width width of keratinized tissue (KT) \&Recession depth (RD) were recorded with William's probe (University of Michigan1,2,3,5,7,8,9 \& $10 \mathrm{~mm}$ ) while gingival thickness (GT) was recorded with reamer and rubber stopper as the protocol mentioned by Arocaet al. 2009,p.245-48.(Fig.-3).Recession depth (RD) was $3 \mathrm{~mm}$ pre-operatively while recession width (RW) was calculated to be about $4 \mathrm{~mm}$ (Fig.-1 \& 2). Width of keratinized tissue came to be around $4 \mathrm{~mm}$ (Fig.-2) while gingival thickness (GT) was $1 \mathrm{~mm}$, pre-operatively (Fig.-3).Full mouth scaling and root planing was done by hand and ultrasonic instruments, at least $4-5$ weeks prior to the surgery and oral hygiene instructions were given and reinforced at each visit. After completion of phase I therapy, patients were scheduled for surgical phase.

\subsection{Recordings of clinical parameters}

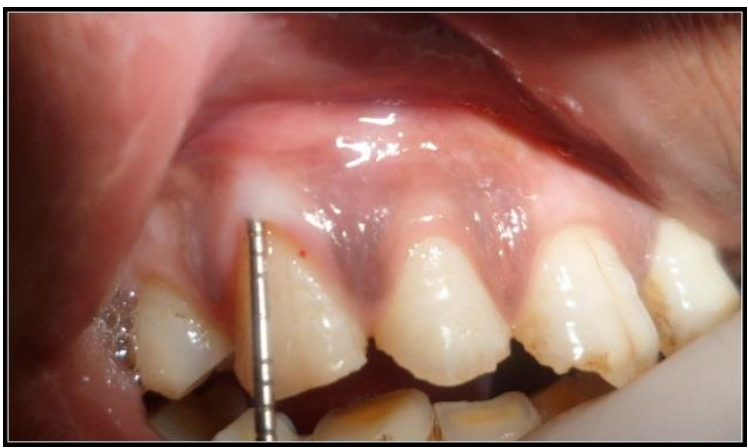

Fig. 2: Recording of Recession Depth, Recession Depth and Keratinized Tissue.

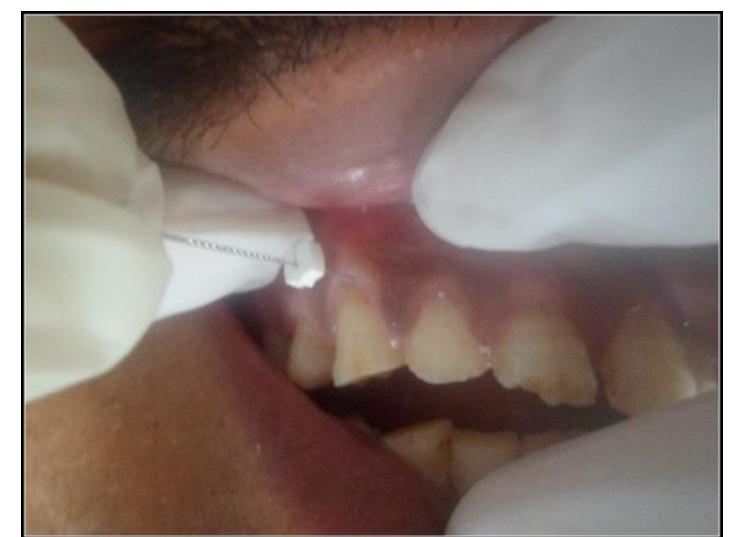

Fig. 3: Recording of Gingival Thickness with Endodontic Reamer.

\subsection{Surgical procedure}

After proper blood investigations, the patient was given written and verbal information on the nature, risks and benefits of the surgical procedure and a signed, informed consent was obtained prior to the treatment .After giving adequate local anaesthesia [2 $\%$ lignocaine hydrochloride with adrenaline 1:200000], the recipient site was prepared for coronally advanced flap (CAF). Allen \& Miller's (1989) technique of Coronally advanced flap was followed in this case (Allen \& Miller 1989 p.38-39; Lindheet al. 2008, p.976). Using No. 15 Bard Parker blade, 2 apically divergent vertical releasing incisions extending from a point coronal to the CEJ (cemento-enamel junction) at the mesial and distal line axis were given towards the lining mucosa (Fig.-4). Then, a split- thickness flap was prepared by sharp dissection at mesial and distal portions of the recession defect. These portions were interconnected by an intra-crevicular incision (Fig.-4). Apical to the receded soft tissue margin on the facial aspect of the tooth, a fullthickness flap was elevated by using Molt's Periosteal elevator (No. 9) to achieve maximum thickness for root coverage (Fig.-5). Approximately $3 \mathrm{~mm}$ apical to the marginal bone, a horizontal incision was made which was followed by blunt dissection into the vestibular lining mucosa so that muscle tension was relieved. This blunt dissection was extended buccally and laterally to make the mucosal graft tension free while positioning it coronally at the level of CEJ. Then, the facial portion (mesial and distal portion of interdental papilla coronal to flap) was de-epithelialized using currette/ cuminescaler to allow for the final placement of the flap margin. Proper isolation was done by using cotton rolls and an 
orthodontic button was cemented/fixed at the central most area of the crown of the involved tooth (Fig.-4). After that, platelet-rich

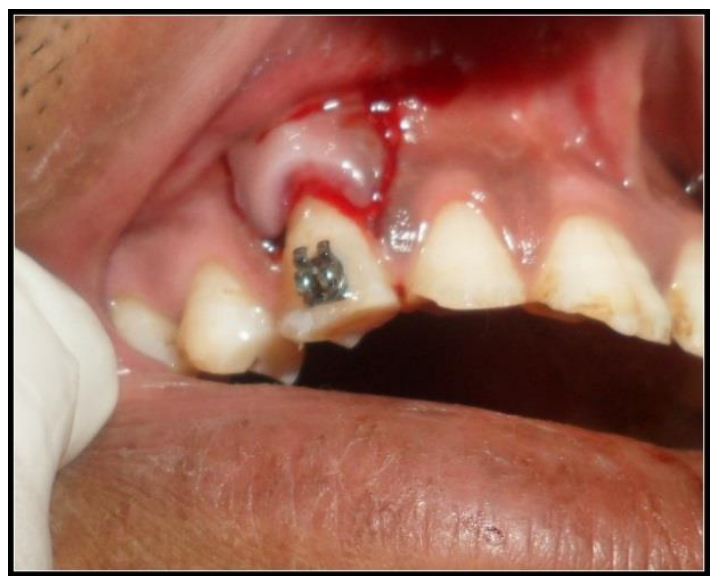

Fig. 4: Vertical and Crevicular Incisionsgiven and orthodonticbracket applied

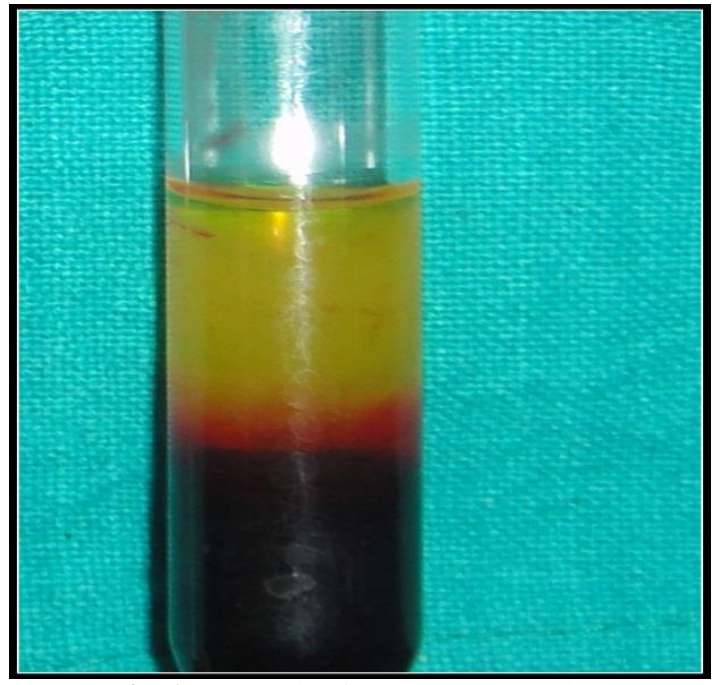

Fig. 6: Platelet-rich fibrin (PRF)preparation.

\subsection{Prf preparation}

The PRF was prepared following the protocol developed by Choukroun et al (2001). Just prior to the surgery, intravenous blood (approx.10 ml) was collected without anticoagulant, by venepuncturing the anticubital vein with the help of $10 \mathrm{ml}$ syringe and was immediately transferred to a glass test tube. The test tube was immediately centrifuged at $3000 \mathrm{rpm}$ for 10 minutes at room temperature.

After centrifugation, blood settles into 3 layers (Fig.6):

1) Red lower fraction containing RBCs.

2) PRF clot in the middle.

3) Upper straw colouredAcellularPlasma.

The PRF clot was removed from the test tube using sterile tweezers, separating it from the RBC base and placed in a sterile dappen dish (Fig.-7, 8). Excess plasma was squeezed out with the gauze and then it was compressed with gauze so that it can be converted into a membrane (Fig.-9)

The membrane was placed on the denuded root and sutured (sling suture) by using $1 / 2$ round cutting needle with 5-0 absorbable fibrin membrane (PRF-M) was prepared.

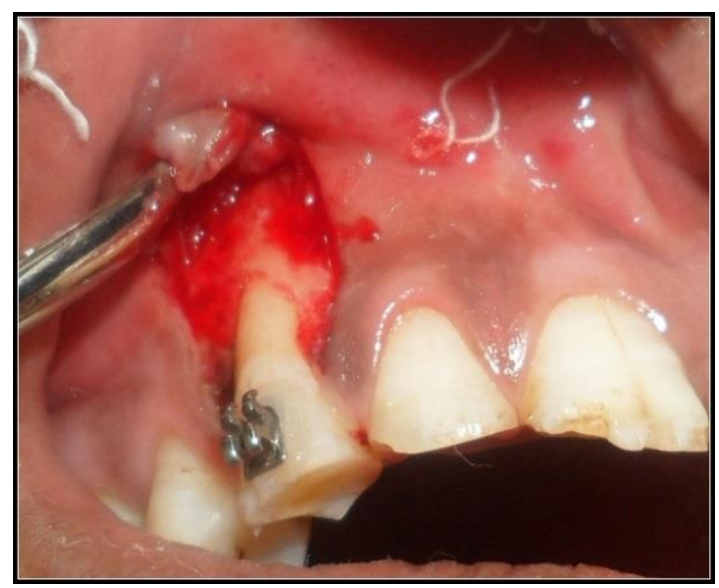

Fig. 5: Raising of Flap beyondMucogingival Junction.

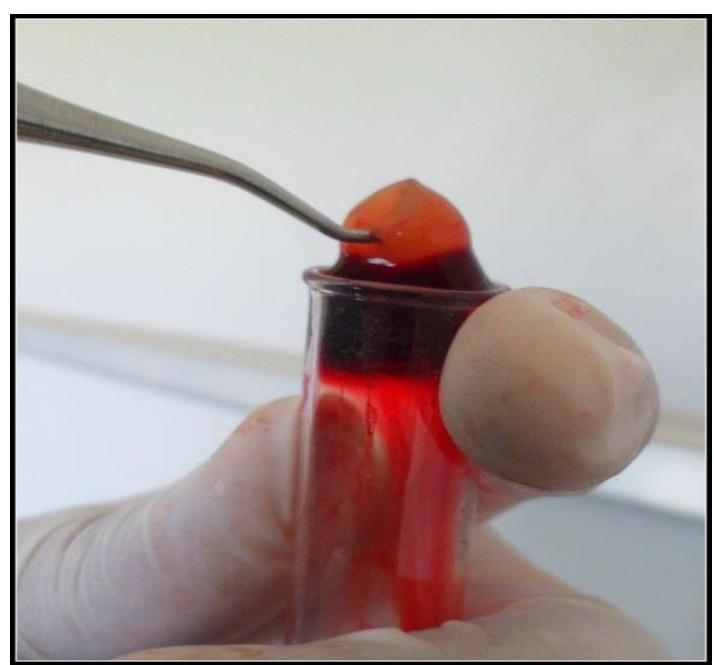

Fig. 7: Isolation of PRF from GlassTest Tube.

chromic gut sutures (Fig.-10).After that, the flap was coronally advanced,adjusted foroptimal fit to the prepared recipient bed andsecured at the level of the CEJ by suturing(interrupted \& sling sutures) the flapto the connective tissue bed in the papilla with 4-0 non-absorbable braided silk sutures (Fig.11). The central area of the flap was stabilized by suturing (sling suture) it to an orthodontic button/bracket and a periodontal dressing (coepack) was given to avoid any direct trauma to the working/operative site.

Patient was prescribed the necessary antibiotics, analgesics, antiinflammatory drugs and chlorhexidine mouthwash $(0.2 \%)$. Routine verbal and written post-surgical instructions were given to the patient and the patient was asked to report after one week, for suture removal and at any time, in case of an adverse event. Thepatient was placed on a soft diet for a period of 10 days and packing was changed after a week and further, placed for another 5 to 7 days for stability. He was told to apply minimal pressure during brushing and use a soft nylon bristle brush during then extend upto 2 to 3 weeks following pack removal. Recall was done after 3 and 6 months. 


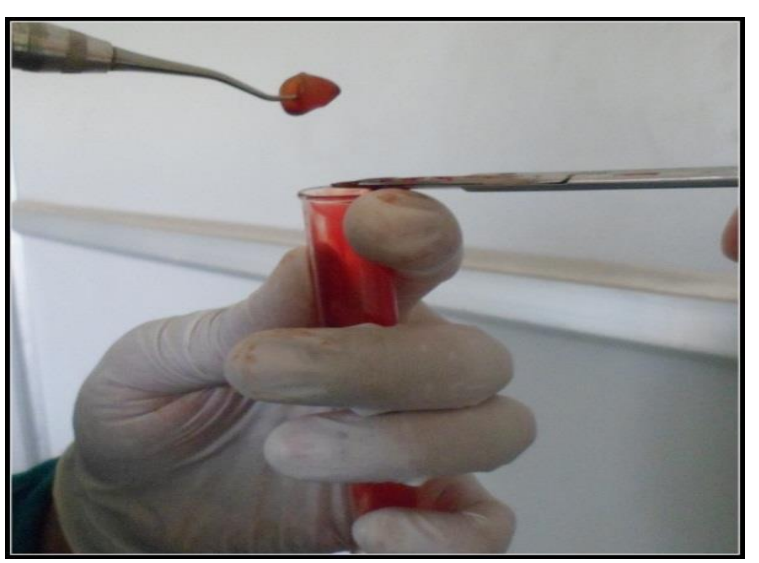

Fig. 8: Separation of Rbcs from PRF.

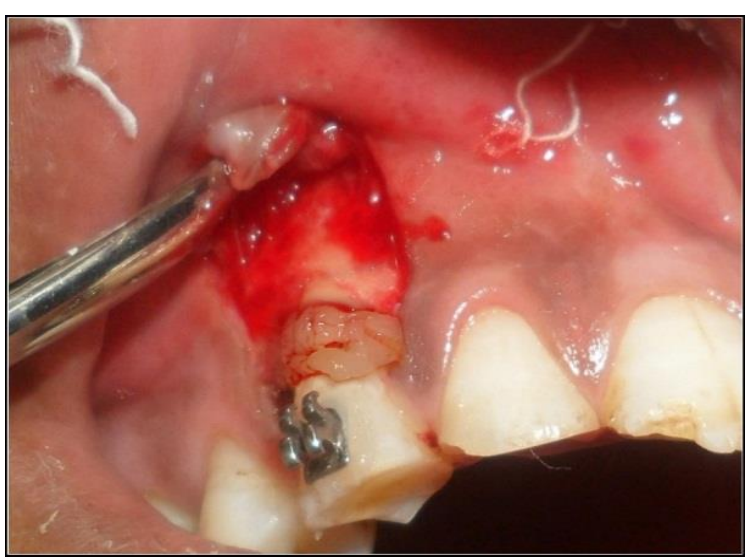

Fig. 10: Application of PRF Membrane.

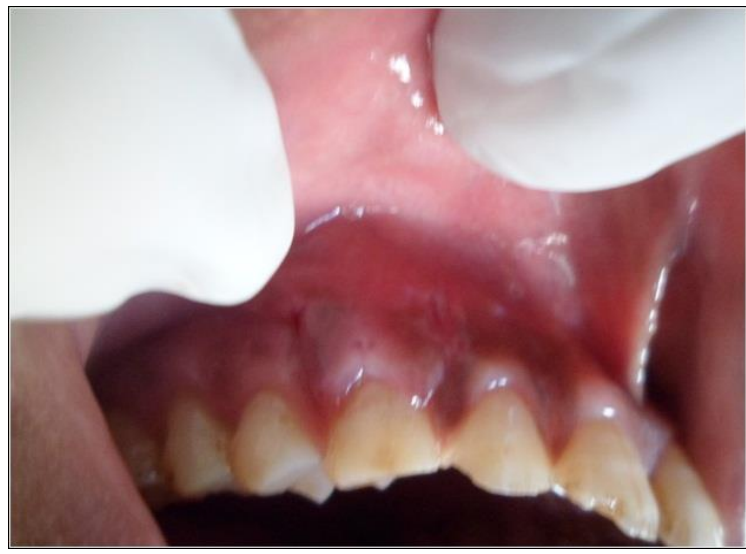

Fig. 12: Post-Operative View after 1week

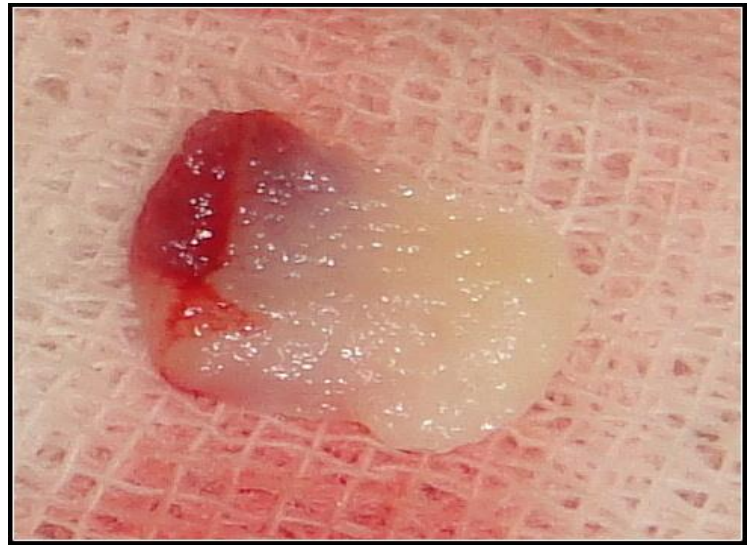

Fig. 9: PRF Membrane Prepared.

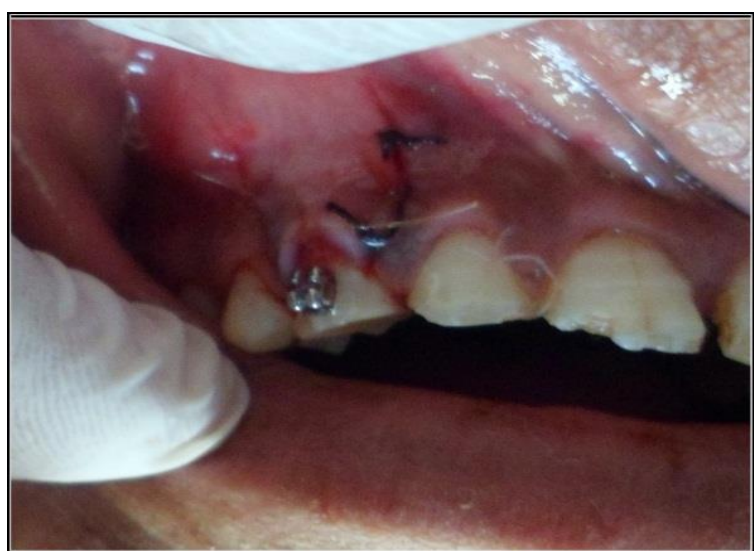

Fig. 11: Sutures Given

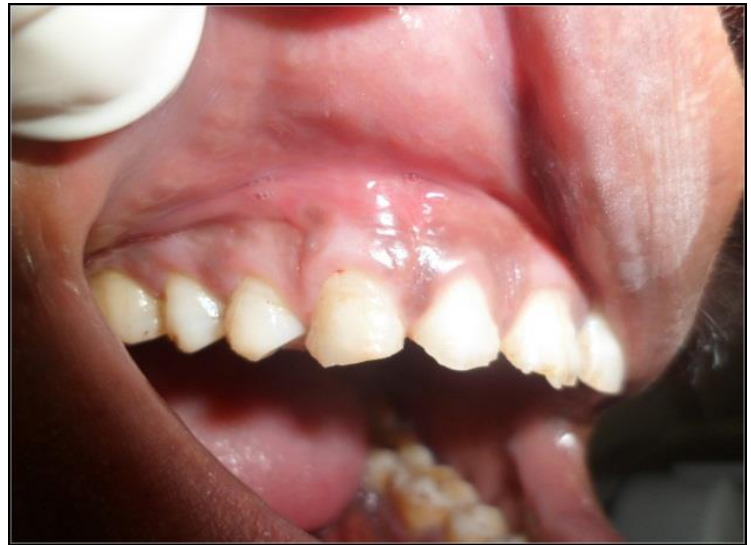

Fig. 13: Post-Operative View after 6 Months

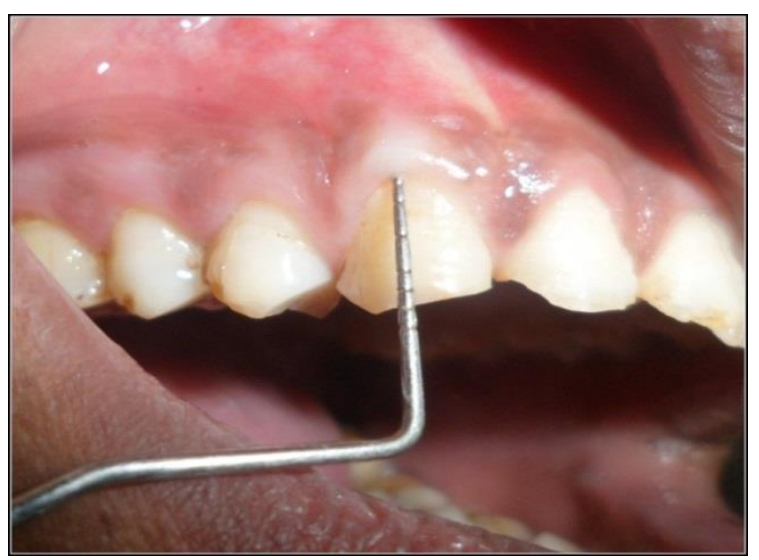

Fig. 14: Recording of allClinical Parameters Showing Complete Root Coverage.

As mentioned earlier, recalling was done after 7 days, 3 and 6 months and all clinical parameters were recoded (Fig.-12,13,14)
There was complete root coverage and healing was uneventful. Also, there were no post-operative complications. 


\section{Results}

The amount of root coverage was determined by calculation of recession depth /width reduction. It was calculated in percentage (\%) (Zucchelli\&Sanctis2000, p.1510): i.e.

Initial recession depth or width-Final recession depth or widthX100

Final recession or width

Recession depth (RD) reduced from $3 \mathrm{~mm}$ pre-operativelyto $0 \mathrm{~mm}$ post-operatively while Recession width (RW) decreased preoperatively from $4 \mathrm{~mm}$ pre-operatively to $0 \mathrm{~mm}$ post-operatively demonstrating $100 \%$ root coverage. Width of keratinized tissue (KT) also increased to $5 \mathrm{~mm}$ from $4 \mathrm{~mm}$ post-operatively. Gingival thickness (GT) increased to $1.5 \mathrm{~mm}$ from $1 \mathrm{~mm}$ postoperatively.

\section{Discussion}

Healing is a crucial phenomenon after the completion of any surgical procedure is over. It is associated with a complex process comprising of both intracellular and extracellular events that are regulated by some signaling proteins. It is not completely understood, but it is quite obvious that, platelets play a major role in formation of blood clot (Guyton \& Hall 2015, p.457). Platelet activation in response to tissue damage and vascular response results in formation of a platelet plug and blood clot which help in providing hemostasis and secretion of biologically active proteins (Eppleyet al.2006,p.147e-159).Presence of Fibrin matrix is useful in acting as a scaffold for the undifferentiated mesenchymal cells which are responsible for facilitating their differentiation thereby, aiding in tissue regeneration (Khiste\&Tari2013;p.16).Directinteraction between fibrin and the osseous tissue has no supportive evidence. But, bone morphogenic proteins (BMP) enmeshed in fibrin matrix have the ability to be released consistently highlighting the angiogenic, hemostatic and osteo conductive properties (Khiste\&Tari2013; p.1-6).Fibrin has the credit of acting as a supportive matrix for BMP. BMPs enmeshed in fibrin are progressively released and are able to induce boneformation. Consistent release of vacular endothelial growth factor (VEGF), fibroblast growth factor (FGF) and platelet derived growth factor (PDGF) helps in angiogenesis. Hemostasis is achieved through the ability of fibrin clot to trap circulating stem cells, allowing vascular and tissue restoration (Khiste\&Tari2013; p.1-6).

Ross et al(1974) was among the pioneers who first described growth factors from platelets (Khiste\&Tari,2013,p.1-6).Plateletrich plasma (PRP) was introduced for the first time by Marx et al in 1998(Khiste\&Tari2013;p.1-6).This biomaterial was advantageous as it was easy to handle and did not provoke chances of infectious diseases (Kauret al.2011, p.86-89).But, it was suggested that there was release of growth factors for a shorter period of time and antibodies to bovine factor Va might cross react with human factor $\mathrm{Va}$ and might produce coagulopathies and rare bleeding episodes.(Kauret al. 2011 p.86-89; Harmon et al.2011,p.8-9).It is contraindicated in patients having Platelet dysfunction syndrome or Critical thrombocytopenia and who are sensitive to bovine antigen (Harmon et al.2011, p.8-9)

This led to the development of platelet-rich fibrin (PRF), a $2^{\text {nd }}$ generation platelet concentrates (natural concentrate is produced without any anticoagulants or jellifying agents.) having various components like fibrin matrix polymer, blood aggregates like platelet derived growth factor (PDGF) and transforming growth factors (TGF- $\beta$ ), cytokines, leucocytes and circulating stem cells (Zhao et al.2013, p.3-5).It was found that the use of platelet-rich fibrin eliminates the need for donor tissue grafting along with fewer amounts of post-operative discomfort(Huang et al.2005, 1770-1774).It is produced by a simple method, safer than PRP, does not require any anticoagulant or bovine thrombin, is costeffective and readily available due to which it has been utilized in various treatment modalities like orthopaedic sand plastic surger- ies (Zhao et al. 2013, p.3-5).The presence of leukocytes and various cytokines enables the self-regulation of the infectious and inflammatory processe(Kauret al. 2011, p.86-89).Various studies have concluded that PRF has a proliferatives effect on different types of cells such as dental pulp cells, human osteoblasts, human gingival and periodontal ligament fibroblasts, dermal prekeratinocytes and preadipcytes (Tsai et al.2009 p.130; Wu et al.2012p.207,Urazet al.2013,p.1).

As already mentioned, amount of keratinized gingiva plays a very crucial role in preventing recurrence of recession. In the past, graft procedures like free gingival/connective tissue graft have proven to be quite successful in increasing the width of keratinized gingiva (Paulo et al.2001 p.78-81; Zucchelliet al.2003, p.864-867).But, both these procedures were associated with painful post-operative discomfort and technique sensitivity (Paulo et al.2001 p.84-88; Zucchelliet al.2003, p.864-867). Advanced flaps (both semilunar and Coronally advanced flaps) are comparatively not so painful, atraumaticin nature and are also technically easy ( Zucchelliet al.2004 p.1737; Joshi \& Gupta 2016, p.41300).But, increase in the width of attached gingiva is not so much significant in performing them (Jankovicet al.2010,p.260).Also, it has been reported that CAF when used alone is unstable on a long-term basis (though there are chances of low morbidity)(Jankovicet al.2010,p.268-70). Even then, it does not always result in the regeneration of attachment apparatus such as cementum, periodontal ligament (PDL) and alveolar bone, which is a major risk factor in recurrence of gingival recession. Considering these facts, addition of PRF was done to coronally advanced flap so that there is enhancement of the healing potential of soft tissues and additional benefits are provided in terms of root coverage and gingival harmony. An orthodontic button/bracket was also applied to provide maximum coronal positioning and stabilization of CAF during the first two weeks (Marooet al.2014 p.132; Fatima et al.2014, p.171).

There was complete root coverage along with increase in the width of attached gingiva in all the cases performed. Healing was uneventful in nature and minimum post-operative painwas observed .This can probably be explained due to inherent effect of growth factors in PRF and avoidance of donor site (Jankovicet al. 2012 ,p.e48-49).Also, increase in the width of attached gingiva can be attributed to the proliferation of gingival and periodontal fibroblasts due to presence of growth factors in PRF (Jankovicet al. 2012,p.e48-49).Even, there was an increase in the gingival thickness which may be due to the influence of growth factors fromPRF or to a spacing effect of the PRF membrane under the gingiva (Arocaet al. 2009, p.247-250).

But, this biomaterial too have certain limitations. It can't be used in uncooperative patients, not willing to give blood and who are suffering from Platelet dysfunction syndrome or Critical thrombocytopenia(Harmon et al.2011, p.8-9).Also, the success of PRF preparation depends on the speed of blood collection and transfer to the centrifuge machine. Since there is absence of anticoagulant, the blood samples still start to coagulate immediately on contacting the tube glass .Another limitation is that the dehydration and inadequate volume of the membrane can result in failure of the PRF membrane (Arocaet al.2009, p.247-250).

Quick handling is the only way to obtain clinically usable PRF clot (Zhao QM et al.2013p.4-5).In my case, the technique of PRF preparation was followed carefully, and it was prepared immediately before placement into the recession defect. Also, it was observed that the applications of orthodontic/button and sling sutures were quite effective in maintaining the coronal displacement of the flap during the first two weeks (Marooet al.2014 p.132; Fatima et al.2014, p.171)

\section{Conclusion}

Application of PRF as an adjunct to the Coronally advanced flap is a beneficial process for increasing the width of keratinized gingiva and achieve uneventful healing. Coronal stabilization during 
first two weeks of Coronally advanced flap adds to its long-term stability. However, dehydration and inadequate volume of the membrane can be responsible for causing failure of the PRF membrane and therefore, there is a need to quickly handle is the PRF clot.

\section{References}

[1] Newman MG, Klokkevold PR, Takei HH, Carranza FA. Carranza's clinical periodontology. 10th edition. Missouri: Saunders Elsevier; 2006.

[2] Raetzke PB. Covering localized areas of root exposure employing the "Envelope Technique". J Periodontol. 1985; 56: 397-402. https://doi.org/10.1902/jop.1985.56.7.397.

[3] Lindhe J, Lang NP, Karring T. Clinical periodontology and implant dentistry.5th edition. Oxford: Blackwell Munksgaard; 2008.

[4] Miller PD. Root coverage associated with the Free gingival graft: Factors associated with incomplete coverage. J Periodontol.1988; 58: 674-681. https://doi.org/10.1902/jop.1987.58.10.674.

[5] Sato N. Periodontal surgery: A clinical atlas.2nd edition. Illinois: Quintessence Publishing Co. Inc; 2000.

[6] Paulo M, Melnick P, KemiyB. The use of free gingival grafts for aesthetic purposes. Periodontal 2000; 2001: 72-96.

[7] HuangHL, Neiva EF, Soehren ES, Giannobile VW, Wang H.The effect of Platelet-Rich Plasma on the Coronally advanced flap root coverage procedure: A pilot human trial.J Peri-odontol. 2005; 76: 1768-77. https://doi.org/10.1902/jop.2005.76.10.1768.

[8] Zucchelli G, Cesari C, Amore C, Montebugnoli L, De Sanctis M Laterally Moved, Coronally Advanced Flap: A Modified surgical approach for isolated recession-type defects.J Periodontol. 2004; 75:1734-41. https://doi.org/10.1902/jop.2004.75.12.1734.

[9] Bernimoulin JP, Luscher B, Muhlemann HR. Coronally repositioned periodontal flap. Clinical evaluation after one year. J Clin Periodontol.1975; 2: 1-13. https://doi.org/10.1111/j.1600051X.1975.tb01721.x.

[10] Kanakamedala A, Geetha A, Umasudhakar, Ramakrishnan T, Vijayalakshmi R, PameelaE. Platelet-rich-fibrin: A novel root coverage approach.J Indian SocPeriodontol. 2009; 13: 50-4. https://doi.org/10.4103/0972-124X.51897.

[11] Castellanos AT, de la Rosa MR, de la Garza M, Caffesse RG. Enamel matrix derivative and coronal flaps to cover marginal tissue recessions. J Periodontol. 2006; 77: 7-14. https://doi.org/10.1902/jop.2006.77.1.7.

[12] Uraz A, Sezgin Y, Yalim M, Taner IL, CetinerD. Comparative evaluation of platelet-rich fibrin membrane and connective tissue graft in the treatment of multiple adjacent recession defects: A clinical study. J Dent Sci. 2013; 10: 1-10.

[13] Zhao QM, Ding YJ, Si T. Platelet-rich fibrin in plastic surgery. OA Evidence -Based Medicine. 2013; 1: 1-6. https://doi.org/10.13172/2053-2636-1-1-512.

[14] Dohan MD, Choukroun J, Diss A, Dohan LS, Anthony J, Dohan J, Mouhyi J, Gogly B.Platelet-rich fibrin (PRF): A second-generation platelet concentrate. Part I: Technological concepts and evolution. Oral Surg Oral Med Oral Pathol Oral RadiolEndod. 2006; 101:3744. https://doi.org/10.1016/j.tripleo.2005.07.008.

[15] KumarAP, KumarC, NagasriM, PadmaR, ShilpaA, Sreedhar A. A split mouth randomized controlled study to evaluate the adjunctive effect of platelet-rich fibrin to coronally advanced flap in Miller's class-I and II recession defects. J Indian SocPeriodontol. 2013; 17: 631-36. https://doi.org/10.4103/0972-124X.119281.

[16] ThamaraiselvanM,Elavarasu S,Thangakumaran T, Sharanabasappa G, Arthie TJ Indian SocPeriodontol. 2015; 19(1): 66-71. https://doi.org/10.4103/0972-124X.145790.

[17] Maroo S, Grover HS, Luthra S. Button-assisted Coronally advanced flap: An innovative Ortho-perio amalgamation. J IndOrthod Soc. 2014; 48(2):129-133. https://doi.org/10.5005/jp-journals-100211231.

[18] Guyton AC, Hall JE.Textbook of Medical physiology.11th edition. India; Elseviers Saunders: Philadelphia; 2006.

[19] EppleyBl, Pietrzak WS, Blanton M. Platelet-Rich Plasma: A review of biology and applications in plastic surgery. Plastic reconstructive surgery.2006; $118 \quad(6): 147 \mathrm{e}-\quad 59 \mathrm{e}$ https://doi.org/10.1097/01.prs.0000239606.92676.cf.

[20] Khiste S, Tari R. Platelet-Rich Fibrin as a biofuel for tissue regeneration. ISRN Biomaterial. 2013; 1-6.

[21] Kaur P, Puneet, Dahiya V. Platelet-Rich Plasma: A novel Bioengineering concept.Trends BiomaterArtif Organs. 2011; 25: 86-90.
[22] Harmon K, Hanson R, Bowen R, Greenberg S, Magaziner E, Vandenbosch J, Harshfield D, Shiple B, Audley D. Guidelines for the Use of Platelet Rich Plasma. The International Cellular Medical Society.2011;1-19.

[23] Wu CL, Lee SS, Tsai CH, Lu KH, Zhao JH, Chang YC. Plateletrich fibrin increases cell attachment, proliferation and collagenrelated protein expression of human osteoblasts. Aust Dent J.2012 57: 207-212. https://doi.org/10.1111/j.1834-7819.2012.01686.x.

[24] Tsai CH, Shen SY, Zhao JH, Chang YC. Platelet-rich fibrin modulates cell proliferation of human periodontally related cells in vitro. J Dent Sci. 2009; 4: 130-35. https://doi.org/10.1016/S19917902(09)60018-0.

[25] Jankovic S, Aleksic Z, Milinkovic I, Dimitrizevic B. The Coronally advanced flap in combination with Platelet-rich fibrin (PRF) and Enamel matrix derivative in the treatment of gingival recession: A Comparative study. Eur J Esthet Dent. 2010; 5: 260-73.

[26] Zucchelli G, Amore C, Sforza NM, Montebugnoli L, De Sanctis M. Bilaminar techniques for the treatment of recession-type defects. A comparative clinical study. J ClinPeriodontol. 2003: 30: 862-870. https://doi.org/10.1034/j.1600-051X.2003.00397.x.

[27] Joshi B,Gupta R.Semilunar flap- Atraumatic suture -less technique for managing gingival recession ; Case series. IJCR. 2016;8 (11):41300-41303. https://doi.org/10.24941/ijcr.2017

[28] Fatima Z, Bey A, Mian F, Zia A. Management of gingival recession using Coronally advanced flap combined with Bracket application: A CaseReport. J Adv Med Dent Scie. 2014;2 (2):171-75.

[29] JankovicS, Klokkevold P, Dimitrizevic B, Kenney BE, Camargo P. Use of Platelet-rich fibrin membrane following treatment of gingival recession: A randomized clinical trial. IntJ Periodontics Restorative Dent.2012; 32: 41-50.

[30] Aroca S, Keglevich T, Barbieri B, Gera I, Etienne D.Clinical evaluation of a modified Coronally advanced flap alone or in combination with a Platelet-rich fibrin membrane for the treatment of adjacent multiple gingival recessions: A 6-month Study. J Periodontol. 2009; 80: 244-52. https://doi.org/10.1902/jop.2009.080253.

[31] Allen EP, Miller PDjr.Coronal positioning of existing gingiva: Short term results in the treatment of shallow marginal tissue recession. J Periodontol. 1989; 60: 316-19. https://doi.org/10.1902/jop.1989.60.6.316. 